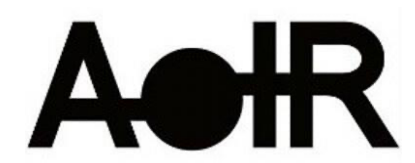

Selected Papers of \#AoIR2021:

The 22nd Annual Conference of the Association of Internet Researchers Virtual Event / 13-16 Oct 2021

\title{
INFLUENCER CULTURE \& ALGORITHMIC APARTHEID ON GAY INSTAGRAM
}

Tyler Quick, University of Southern California

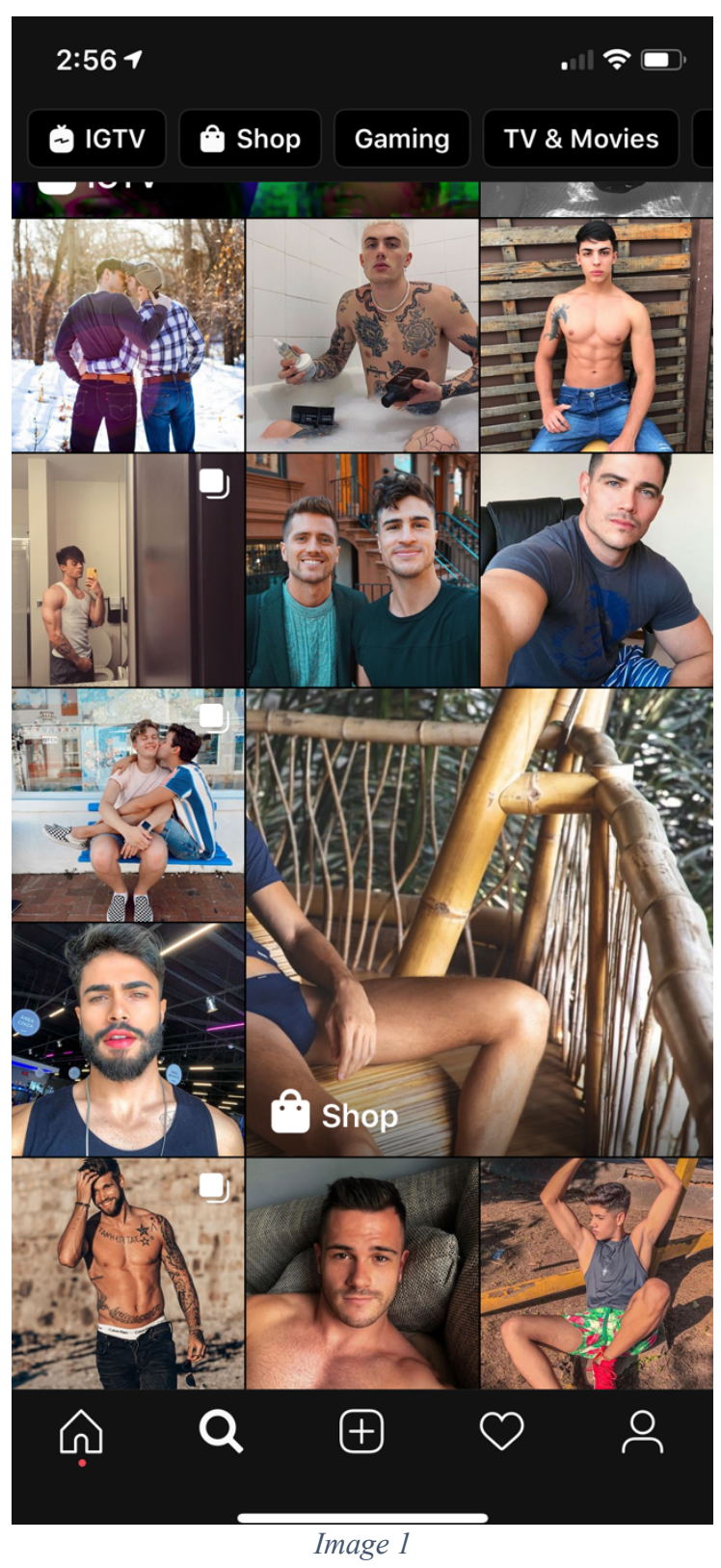

Introduction Critical research on social media influencers has concluded that influencers' status is always contingent upon laboring to meet followers' demand for "performances-of-self," as well as making these performances available and visible (e.g. see Baym 2018, Duffy \& Hund 2019, Duguay 2019). However, few have addressed the role that algorithms play in determining which influencers might be made visible, and therefore how platform design can predetermine who may attain influencer status. This project seeks to address this gap in the research by providing critical ethnographic insights into what is colloquially referred to as "gay Instagram." "Gay Instagram" is a term deployed by gay men to describe the social milieu and algorithmicallydetermined field of visibility in which gay men produce and consume content intended for consumption by other gay men. While such content varies, gay Instagram has become increasingly understood by gay men as a space that has "morphed from being a social network for friends to a sea of semi-nude 'influencer' accounts" (Scher 2019). Gay men who have interacted with homoerotic content on Instagram frequently report being subjected thereafter to images of "Instagays"- popular gay influencers who specialize in homoerotic self-representation-in their promoted content and on the "explore page," oftentimes to the extent that this content eclipses all other kinds (see image 1). What this makes clear to me is that the algorithmic processes that mediate whose content is made visible in order to sate Instagram audiences' scopophilic desires

Suggested Citation (APA): Tyler, Q., (2021, October). Influencer Culture \& Algorithmic Apartheid on Gay Instagram. Paper presented at AoIR 2021: The 22nd Annual Conference of the Association of Internet Researchers. Virtual Event: AolR. Retrieved from http://spir.aoir.org. 
conceptualize the supply and demand of homoerotic imagery in a manner that compounds existing social biases and further privileges the visibility of the white, Western, and wealthy gay person.

Methodology: My work draws upon Rob Kozinets' (2020) "netnographic" approach to online field work. Such an approach combines best practices from a number of methods and disciplines to provide a data-rich description of expansive and unwieldy online phenomena such as mine. Throughout a period of three years, I maintained an Instagram account through which I produced and disseminated my own homoerotic content, interacted with followers and other content creators, and observed trends in the production and consumption of homoerotic content. During this time, I maintained a "field notes" journal that included my written observations, along with over two thousand posts produced by others that I collected, coded, and categorized, screenshots of "algorithmic audits" (Brown et al. 2021) I performed, aggregated social media data collected from Social Blade, and over one hundred articles collected from popular and LGBTQ press coverage of "Instagays" and "gay Instagram."

However, as a queer scholar, I am suspicious of attempts to "redeem" ethnography (see Cornejo 2019), especially in digital circumstances. Applications like Instagram are designed to respond rapidly to new input data, leaving even a single Instagram user's experience of the app liable to change drastically in the span of a day. As such, even methods like "algorithmic audits" can only definitively demonstrate the appearance of a specific output in response to input variables that are proprietary information and thus unknowable (Seaver 2019; 2021). I mention this not to disparage my research, but rather to state an ideological position: observational methods can only describe subjective experiences of social media. However, as a member of the community I am studying, my subjective experience, albeit ungeneralizable, is in its own way representative of my phenomenon. By coupling it with a discourse analysis of media coverage of my phenomenon, and a wealth of data provided by analyzing comments, interviewing influencers, etc., I offer a multi-perspectival, interdisciplinary account of Instagram. Seeing as a definitive account is impossible, such will have to do for now.

Data Summary: Once Instagram has determined that a user is interested in homoerotic content, that user can almost always expect the overrepresentation of white, mostly American Instagays on their "explore page," in the promoted content featured on their feed, in the suggested accounts to follow when they follow new people, and, if they are already following Instagays, at the top of their feed whenever they log onto the app. In fact, when I created a second Instagram account on a different device as a sort of experiment to see if a change in IP address or identity might affect the content made visible to me, my explore page became saturated with white, American Instagays after only three days of interacting with Instagays' accounts.

Whenever I followed nonwhite or non-American Instagays, many of the suggested accounts that appeared underneath the influencer were white and/or American, This suggests that in such circumstances Instagram interprets general demand for homoeroticism as "colorblind" (arguably an act of racial discrimination itself, see BonillaSilva 2003) and responds by merely supplying it with the most popular Instagays, who are invariably Western and white or white-passing. Moreover, in the instances in which I 
followed white Instagays, I almost never was suggested to follow people of color. In fact, at times I would often be suggested white gay men's accounts with relatively few followers, but who were socially or romantically connected to popular white Instagay accounts. This all leaves the impression that when determining the content best-suited to supply demand for homoeroticism, Instagram's algorithmic infrastructure is most likely to guide gay men toward accounts who bear the most "affinity" (Mahapatra 2020) with the most popular accounts, which often in practice means those accounts already within influencers' social environments.

Conclusion: The seeds for stratification along national and racial lines among the Instagay class along racial and national lines were long ago sown, as the input data determining affinity and thus visibility is already marked by disproportionate demand among (Western) gay men for white homoeroticism, i.e. sexual racism (see Han \& Choi 2018). However, this is not the only manner by which Instagram's platform design determines algorithmic visibility for aspiring influencers. The data I present above (and in far greater depth in this presentation), suggests that "affinity" can also be determined through engagement between accounts, i.e. an account frequently engaged with by an Instagay is more likely to be made visible to his followers. In effect, determinations of the most desirable homoerotic content are made through a variety of methods that make access to visibility an unequal enterprise on Instagram. For many reasons, white elites in Western metropolises are made more visible to Instagram users, even when others could conceivably fulfill their same representational function, troubling the notion that influencer status can be attained through an individual's "labor" without algorithmic assistance.

\section{References:}

Baym, N. (2018). Playing to the Crowd: Musicians, Audiences, and the Intimate Work of Connection. New York: NYU Press.

Bonilla-Silva, E. (2003). Racism without Racists: Color-blind Racism and the Persistence of Racial Inequality in the United States. Lanham, MD: Rowman \& Littlefield.

Brown, S., Davidovic, J., \& Hasan, A. (2021). The algorithm audit: Scoring the algorithms that score us. Big Data \& Society, 8.

Christin, A. (2020). The ethnographer and the algorithm: beyond the black box. Theory and Society, 49 (5-6), $897-$ 918.

Cornejo, G. (2019). Travesti Dreams Outside in the Ethnographic Machine. GLQ, 25 (3), 457-482.

Duffy, B., \& Hund, E. (2019). Gendered Visibility on Social Media: Navigating Instagram's Authenticity

Bind. International Journal of Communication (Online), 4983-5002.

Duguay, S. (2019). "Running the Numbers": Modes of Microcelebrity Labor in Queer Women's Self-Representation on Instagram and Vine. Social Media + Society, 5 (4), 1-11.

Han, C., \& Choi, K. (2018). Very Few People Say "No Whites": Gay Men of Color and the Racial Politics of Desire. Sociological Spectrum, 38 (3), 145-161.
Kozinets, R. (2020). Netnography: the essential guide to qualitative social media research ( $3^{\text {rd }}$ edition). Los Angeles: SAGE.

Mahapatra, A. (2020, December 16). On the Value of Diversified Recommendations. Retrieved from https://about.instagram.com/blog/engineering/on-the-valueof-diversified-recommendations

Scher, A. (2019, February 22). Are sexy gay Instagram accounts FUELING disordered eating? NBC News.

Retrieved from https://www.nbcnews.com/feature/nbcout/are-sexy-gay-instagram-accounts-fueling-disorderedeating-n974036

Seaver, N. (2019). Knowing Algorithms. In J. Vertesi, D. Ribes, et al. (Eds) digitalSTS: A Field Guide for Science \& Technology Studies. Princeton University Press, 412-422.

Seaver, N. (2021). Seeing like an infrastructure: avidity and difference in algorithmic recommendation. Cultural Studies (ahead-of-print), 1-21. 